\title{
Perinatal Mortality Review in a Tertiary Care Hospital: Way Forward to Address SDG Health Goal 3
}

\section{Manisha Bajracharya', Ang Tshering Sherpa', Ajaya Kumar Dhakal', Sunita Bhandari', Heera Tuladharl and Meenu Maharjan ${ }^{1}$}

${ }^{1}$ Department of Obstetrics and Gynaecology, KIST Medical College Teaching Hospital, Imadol, Lalitpur, Nepal

${ }^{2}$ Department of Community Medicine, KIST Medical College Teaching Hospital, Imadol, Lalitpur, Nepal

${ }^{3}$ Department of Paediatrics, KIST Medical College Teaching Hospital, Imadol, Lalitpur, Nepal

\begin{abstract}
Introduction: Sustainable development goal 3 targets at ensuring healthy lives and promoting well-being for all at all ages. One of the component for achievement of this goal is improvement of maternal and child health; the indicators of which is perinatal mortality rate. The aim of this study was to evaluate the cause of perinatal death in a tertiary care medical centre, which may help to reduce the incidence of perinatal death and improve the quality of care.

Methods: A prospective study was done over a period of one year from April 2016 to March 2017. Causes of perinatal deaths based on PSANZ classification were recorded along with patients demographics and also avoidable factors were evaluated.

Results: Out of total 1275 deliveries, there were 21 perinatal deaths including three intrauterine foetal deaths, one still birth and seven early neonatal deaths. The perinatal mortality rate was 16.27 per 1000 birth. Majority of perinatal deaths $(19 \%)$ occurred due to congenital anomalies followed by (14\%) hypertensive disorder in pregnancy, intrapartum hypoxia (14\%), unexplained causes (14\%), 9.5\% cord prolapse, antepartum haemorrhage $(9.5 \%), 5 \%$ due to intrauterine growth restriction, gestational diabetes mellitus or preterm labour. Most of the mothers whose baby had perinatal deaths had ANC outside. Most of the deaths occurred in between gestational age of 37 to 41 weeks. Perinatal mortality was more in multigravida. Delay to seek health care and inadequate antenatal checkups were the most common avoidable factors.

Conclusions: Congenital anomalies and hypertensive disorders during pregnancy were the most common causes of perinatal death. Delay in health seeking behaviour was the most common avoidable factors for perinatal death. We recommend early identification of high risk pregnancy through proper antenatal screening, educating pregnant women to identify danger signs of pregnancy, creating public awareness about importance of antenatal checkups, vigilant labour monitoring for foetal distress, to reduce some categories of deaths.

Key words: Perinatal mortality in Nepal; SDG3 Nepal; Perinatal Audit; PSANZ classification
\end{abstract}

Correspondence: Manisha Bajracharya, Department of Obstetrics and Gynaecology, KIST Medical College Teaching Hospital, Imadol, Lalitpur, Nepal. Email :drmanishabajra@gmail.com

DOI: $10.3126 / \mathrm{mjsbh} . v 18 \mathrm{i} 1.21738$

Submitted on: 2018-05-13

Accepted on: 2018-09-25

This work is licensed under creative common license:

http://creativecommons.org/licenses/by-nc-nd/4.0/ C MJSBH 2018 


\section{INTRODUCTION}

Perinatal death includes death of a baby from 22 weeks of gestation (or baby weighing at least 500 grams) to first seven days of life (early neonatal period). ${ }^{1}$ Sustainable development goal 3 (SDG 3) targets at ensuring healthy lives and promoting well-being for all at all ages. By 2030, target is to end preventable deaths of newborns and children under five years of age, with all countries aiming to reduce neonatal mortality to at least as low as 12 per 1000 live births and under five mortality to at least as low as 25 per 1000 live births. ${ }^{2}$ In 2015, the global Neonatal Mortality Rate (NMR) was 19 deaths per 1,000 live births, a decrease from 31 deaths per 1,000 live births in 2000. Neonatal mortality is highest in Central and Southern Asia and in sub-Saharan Africa, at 29 deaths per 1,000 live births in each of those regions in 2015. Current Infant Mortality Rate (IMR) of Nepal is 21 deaths/ 1,000 live births. ${ }^{2}$ Over the past 15 years, reproductive, maternal and child health have improved greatly. Still many unborn and newborn children die due to reasons which could have been avoided. Therefore this study was carried out to evaluate the preventable causes of perinatal deaths and evaluate the avoidable factors in a tertiary care centre of Nepal so that the preventable root causes are analysed and recommendations could be made which will help in reducing the perinatal mortality

Table1. Number of births, perinatal deaths and mortality rates

\begin{tabular}{|l|r|}
\hline Statistics & Total \\
\hline Total births & 1283 \\
\hline Total live births & 1262 \\
\hline Still births & 11 \\
\hline Intrauterine fetal death & 3 \\
\hline Early neonatal death & 7 \\
\hline Total perintal death & 21 \\
\hline
\end{tabular}

as well as improve the standard of care of the hospital.

\section{METHODS}

A descriptive, cross sectional study was done over a period of one year from April 2016 to March 2017 in a tertiary care teaching hospital in Nepal. Approval was taken from the Institutional Review Board prior to initiation of study. Confidentiality of data were maintained. A preformed questionnaire was developed to record the cause of perinatal deaths according to PSANZ perinatal mortality classification. ${ }^{3}$ Patients demographic data were also collected (maternal age, antenatal checkups, gestational age at delivery), mortality indicators were calculated and the avoidable factors were identified. All the data were entered in the excel and bivariate analysis was done by SPSS 21 . Frequency and proportions were calculated.

\section{RESULTS}

There were total 1275 deliveries during the study period with 21 perinatal deaths which accounts to perinatal mortality rate of 16.27 per 1000 birth. The mortality statistics and mortality indicators are described in tables 1 and 2.

Most of the mothers whose baby had perinatal deaths had ANC outside the institute. Age distribution of the mothers are showed in table 3 . Most of the deaths occurred in between gestational age of 37 to 41 weeks as shown in table 4 . Perinatal mortality was more in multigravida. Majority of

\begin{tabular}{|l|r|}
\hline \multicolumn{2}{|c|}{ Table 2. Mortality indicators } \\
\hline Mortality indicators & Total \\
\hline Still birth rate (per 1000 birth) & 10.91 \\
$\begin{array}{l}\text { Early neonatal death rate (per } 1000 \text { live } \\
\text { birth) }\end{array}$ & 5.55 \\
\hline Perinatal mortality rate (per 1000 birth) & 16.27 \\
\hline
\end{tabular}




\begin{tabular}{|c|c|}
\hline \multicolumn{2}{|c|}{ Table 3. Age distribution of mothers } \\
\hline Age group (Yrs) & Numbers \\
\hline $20-25$ & $8(38 \%)$ \\
\hline $25-30$ & $10(48 \%)$ \\
\hline $30-35$ & $3(4 \%)$ \\
\hline
\end{tabular}

perinatal deaths $(19 \%)$ occurred due to congenital anomalies and hypertensive disorder in pregnancy

(Fig 1). Inadequate or no antenatal check up and delay in seeking health care were the most common avoidable factors identified (Table 5).

\section{DISCUSSION}

Perinatal death audits play vital role not only in reducing the perinatal mortality rate but also signifies the quality of health services of any institution or health care centre. Determination of cause of perinatal death is useful in setting priorities for health interventions and assessing program needs to decrease perinatal mortality. Data on deaths is often limited in Nepal and other
Table 4. Gestational age distribution of perinatal deaths

\begin{tabular}{|l|r|}
\hline \multicolumn{1}{|c|}{ Gestational age (Weeks) } & Perinatal deaths \\
\hline$<28$ & 6 \\
\hline $28-34$ & 6 \\
\hline $34-36$ & 2 \\
\hline $37-42$ & 6 \\
\hline$>42$ & 1 \\
\hline
\end{tabular}

developing countries. The first 28 days of life, the neonatal period, is the most vulnerable time for a child's survival (UNICEF 2015). ${ }^{2}$ Globally, 2.6 million children died in the first month of life in 2016 - approximately 7,000 newborn deaths every day - most of which occurred in the first week, with about 1 million dying on the first day and close to 1 million dying within the next six days. ${ }^{4}$ In Nepal, neonatal deaths and stillbirths remain still an important health problem. Despite efforts made to reduce neonatal deaths, Nepal has witnessed a stagnant NMR of 33 per 1,000 in the preceding five

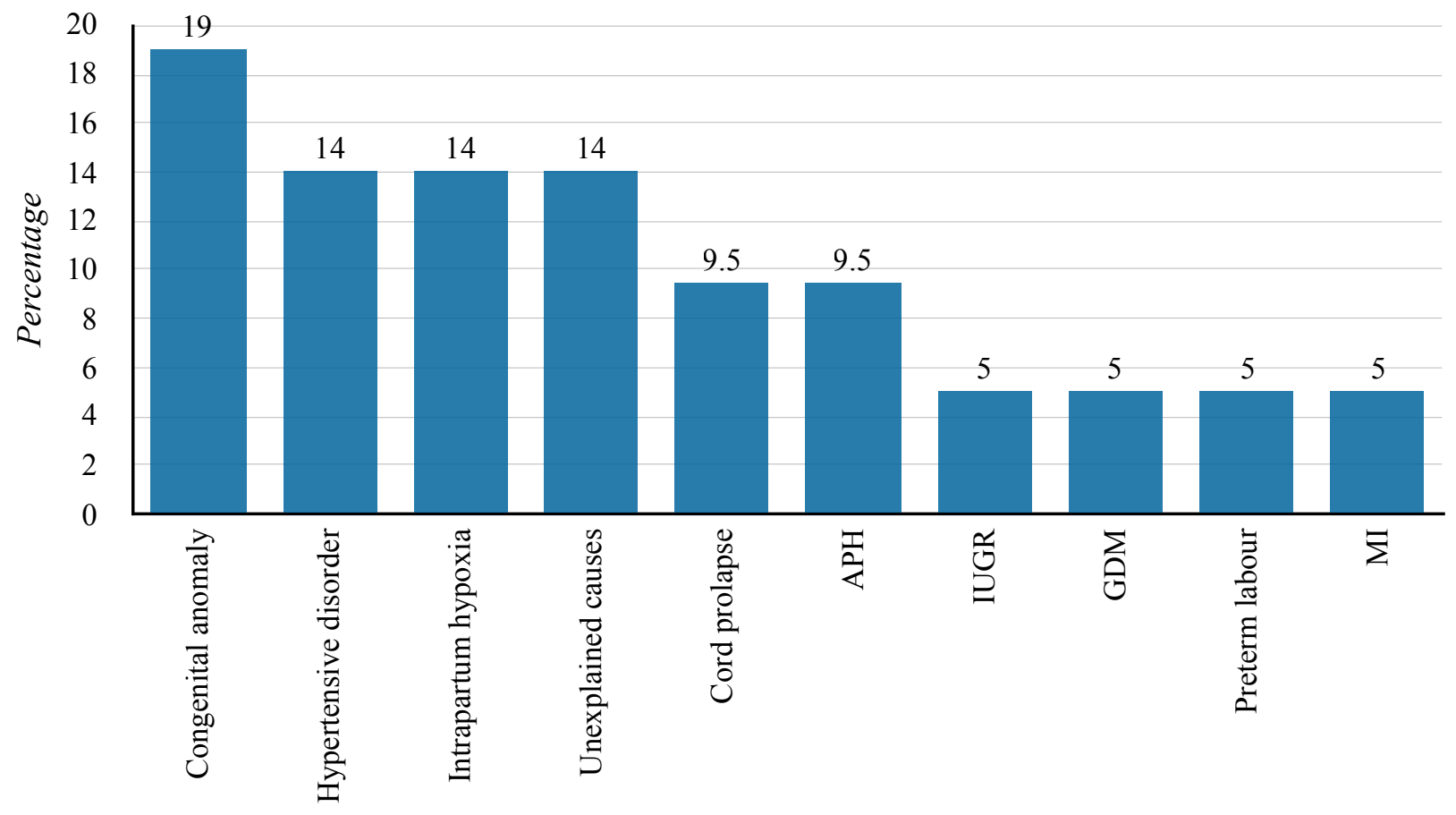

Causes

Fig 1. Causes of perinatal mortality 
Table 5. Avoidable factors

\begin{tabular}{|l|l|}
\hline $\begin{array}{c}\text { Patient related } \\
\text { avoidable } \\
\text { factor }\end{array}$ & \multicolumn{1}{c|}{$\begin{array}{c}\text { Health facility related/ service } \\
\text { provider related avoidable } \\
\text { factor }\end{array}$} \\
\hline $\begin{array}{l}\text { Delay in } \\
\text { seeking care: } 6\end{array}$ & $\begin{array}{l}\text { Lack of proper antenatal } \\
\text { counselling regarding high risk } \\
\text { conditions: } 7\end{array}$ \\
\hline $\begin{array}{l}\text { No/ inadequate } \\
\text { ANC } \\
\text { checkups: } 7\end{array}$ & \begin{tabular}{l} 
Lack of anomaly scans: 5 \\
Lack of initial management of \\
cord prolapse at primary care: 2 \\
Delay in referral: 1 \\
\hline Inadequate labour monitoring: 1
\end{tabular} \\
\hline
\end{tabular}

years as shown by the 2006 and 2011 NDHS surveys. And in 2016 NDHS, NMR has reduced to 21 per 100 live births which denotes we are still far way from reaching our SDG target. Thus, still there is need for a detailed study to find the root causes of neonatal deaths. ${ }^{4}$ And our study focuses on the same objective. Similar to NDHS 2011, the most common cause was due to respiratory and cardiovascular disorder and perinatal asphyxia. ${ }^{5}$ Not only in Nepal but study by Srivastava $\mathrm{S}$ et al. in 2014 in India also had similar finding. ${ }^{6}$ Similarly in South East Asia, child and infant mortality has reduced considerably but the NMR is still high. ${ }^{7}$

A cross-sectional study conducted in Bangladesh reported young maternal age ( $\leq 18$ years) to be associated with perinatal mortality 8 whereas a cohort study done in Pakistan identified that older maternal age ( $\geq 40$ years) was associated with perinatal mortality. 9 But in our studies most perinatal death occurred in the reproductive age group rather than the extreme age groups. Similar to our study in a systematic review done by Pramesh et.al. ${ }^{10}$ in 2018 revealed perinatal mortality in Pakistan, Bangladesh and India were associated with maternal medical conditions, birth and pregnancy complications such as anaemia, ${ }^{11,12}$ antepartum haemorrhage, ${ }^{13,14}$ hypertensive disorders, ${ }^{13}$ congenital anomalies, ${ }^{13}$ placenta and cord abnormalities, ${ }^{15}$ pregnancy-induced hypertension, ${ }^{14}$ probable infection, ${ }^{14}$ and neonatal and intrapartum complications. ${ }^{15,16}$

The study found that perinatal deaths due to congenital anomalies were very common and most patients had their antenatal checkup in health post where ultrasonography facilities are not available. Hence proper antenatal checkup and ultrasonography including anomaly scan is recommended to improve perinatal outcome. In 2003 similar study done in Nepal Medical College by Dali SM revealed unidentified causes and poor antenatal checkups as the most common cause of perinatal deaths. ${ }^{17}$ Whereas study done in Kathmandu Medical College revealed perinatal mortality rate of 30.7 with most important cause being prematurity, birth asphyxia and congenital anomaly. ${ }^{7}$ Unlike studies done in past where the causes of perinatal mortality were identified to be broad like prematurity and birth asphyxia, the root causes and the risk factors leading to these causes in our study were identified by using PSANZ classification of perinatal deaths, which can help in preventing perinatal deaths by identifying the high risk factors at earlier stage and thus reduce the avoidable factor related perinatal mortality for example hypertensive disorder of pregnancy, cord prolapse, intrapartum birth asphyxia, and so on.

Also here in patient related avoidable factors, most patients did not have adequate antenatal checkups and had delay in seeking health care. Regular antenatal checkup holds important aspect in reducing the perinatal mortality rate by identifying the high risk cases, educating mothers about the danger signs so that they seek health care timely so that timely intervention can be done. Though government has built a proper referral system, we found that it is not being followed and there is delay in receiving the health attention by the 
patients. 18 The Family Health Division (FHD) of the Department of Health Services (DoHS) has taken an initiative in developing tools for conducting maternal and perinatal death reviews. The death reviews was initially conducted in three hospitals inside Kathmandu and in three hospitals outside Kathmandu in Nepal. Later on this has been implemented in many hospitals nationwide. Though several programmes have been implemented not only in Southeast Asia, but globally like safe motherhood and neonate programmes, still we need to work hard towards achieving the SDG 3.19 And the regular perinatal audit can help in the shifting paradigm of the perinatal death review system in the country, and hence can facilitate for reaching the SDG 3 target.

From our study we found the need of further study at community level that can be done to find out the cause of delay in seeking health care which can help decreasing these kinds of preventable deaths. Also we need to further strengthen our referral system by appropriate communication and proper feedbacks. However since we have done data analysis of only one year so sample size might not have been adequate, but since our hospital is a tertiary care referral centre we represent both urban and rural population. Ours is a single centred study, if similar perinatal mortality review could be done in entire nationwide we can get the national data. Hence emphasis should be given to reviewing the perinatal deaths which can explore the causes, gaps, and challenges that needed to be overcome. The quality improvement committees at different levels can closely monitor the progress and intervene accordingly to improve the quality of care that is to be given, which not only improves the health care delivery system but also can help in achieving SDG goal 3.

\section{CONCLUSIONS}

Congenital anomalies were found to be most common reason for perinatal deaths, followed by intrapartum hypoxia, hypertensive disorder of pregnancy and unexplained causes. Perinatal deaths were related mostly to delay in seeking the health care and inadequate antenatal checkups. Hence importance of proper antenatal checkups, proper antenatal counselling of high risk conditions and anomaly scan should be emphasised.

To cite this article: Bajracharya $M$, Sherpa AT, Dhakal AK, Bhandari S, Tuladhar H, Maharjan M. Perinatal Mortality review in a tertiary care hospital: way forward to address SDG health goal 3. MJSBH. 2019;18(1):69-74.

\section{Conflict of Interest: None declared}

\section{REFERENCES}

1. "WHO - Maternal and perinatal health". www.who.int.

2. Nepal population report 2016, 2016, p. 1

3. Perinatal deaths in Australia 2013-14: AIHW: Causes of perinatal death 5.1: pg 36.

4. https://data.unicef.org/topic/child-survival/neonatal-mortality/ updated feb 2018.

5. Report on Nepal demographic health survey 2016.

6. Srivastava S, Sharma S, Kharkwal S, Chaudhary V. A study of causes of perinatal mortality in tertiary center in Bundelkhand region. IJRCOG. 2017 Feb;4(1):43-6.

DOI: $10.5455 / 2320-1770$. ijrcog20150208 
7. Shrestha M, Manandhar DS, Dhakal S, Nepal N. Two year audit of perinatal mortality at Kathmandu Medical College Teaching Hospital. KUMJ. 2006;4(2):176-81.

\section{PMID:18603894}

8. Kusiako T, Ronsmans C, Van der Paal L. Perinatal mortality attributable to complications of childbirth in Matlab, Bangladesh. Bull. World Health Organ. 2000;78:621-7.

9. Shabbir S, Zahid M, Qazi A. To detect outcome of pregnancy in advanced maternal age among Pakistani women. Pak. J. Med. Sci. 2014;1:709-12.

10. Ghimire P, Agho K, Akombi B, Wali N, Dibley M, Raynes-Greenow C, et al. Perinatal mortality in South Asia: Systematic Review of observational studies. Int J Environ Res Public Health. 2018 Jul; 15(7):1428. DOI: https://doi.org/10.3390/ijerph15071428

11. Perveen S., Soomro T.K. Sideropaenic anaemia: Impact on perinatal outcome at tertiary care hospital. J Pak Med Assoc. 2016;66:952-6.

12. Bari W, Chowdhury RI, Islam M, Chakraborty N, Akhter H. The differentials and determinants of perinatal mortality in rural Bangladesh. Eur J Contracept Reprod Health Care. 2002;7:216-22.

DOI: https://doi.org/10.1080/ejc.7.4.216.222

13. Iqbal M, Majid A, Khan HA, Muhammad Z. Perinatal mortality and its related obstetrics risk factors. J Med Sci. 2014;22:76-9.

14. Khanam R, Ahmed S, Creanga AA, Begum N, Koffi AK, Mahmud A, et al. Antepartum complications and perinatal mortality in rural Bangladesh. BMC Pregnancy Childbirth. 2017;17:81.

DOI: https://doi.org/10.1186/s12884-017-1264-1

15. Shah D, Shroff S, Ganla K. Factors affecting perinatal mortality in India (perinatal audit) Prenat. Neonatal Med. 2000;5:288-302.

16. Siddalingappa H, Nrayana M, Kulkarni P, Ashok N. Prevalence and factors influencing perinatal mortality in rural Mysore, India. J Clin Diagn Res. 2013;7:2796.

DOI: https://doi.org/10.7860/JCDR/2013/6367.3761

17. Dali SM. Perinatal death audit. Journal of Nepal Medical Association. 2003 November-December; 42:383-6.

DOI: https://doi.org/10.31729/jnma.655

18. http://umeshg.com.np/referral-system-in-nepal/

19. http://www.unicefrosa-progressreport.org/savenewborns.html 